\title{
CREATING PRIMARY CARE ACCESS FOR MENTAL HEALTH CARE CLIENTS IN A COMMUNITY MENTAL HEALTH SETTING
}

\author{
TAMISON DOEY, PAMELA HINES, BONNIE MYSLIK, and \\ JOANN ELIZABETH LEAVEY \\ Canadian Mental Health Association, Windsor-Essex County Branch \\ Windsor, Ontario \\ JAMIE A. SEABROOK \\ Department of Pediatrics, Children's Health Research Institute \\ and Department of Sociology, London Health Sciences Centre \\ London, Ontario
}

\begin{abstract}
Successful support of persons living with a mental illness in the community is challenged by the lack of primary care accessible to this population. The Canadian Mental Health Association-Windsor Essex County Branch explored options to provide mental and physical health care, initially creating an integrated primary care clinic and later a larger community health clinic co-located with its mental health care services and staffed by a multidisciplinary team. A retrospective review of 805 charts and a client satisfaction survey were conducted in 2001 to evaluate this service. Findings indicate that access to primary care and mental health care co-located at a community-based clinic has reduced the number of emergency room visits and admissions, and length of stay in hospital, for individuals with moderate to serious mental illness. A client survey in January 2008 supports these preliminary findings.
\end{abstract}

The last 10 years have seen a growing interest in the provision of primary health care to ensure good outcomes for persons with a serious mental illness. The traditional model utilizing parallel practitioners - a psychiatrist and a primary care provider-is inefficient and ineffective (Unützer, Schoenbaum, Druss, \& Katon, 2006). Yet, primary care providers have been limited in their ability to meet the mental health needs of patients because of lack of training (Leigh, Stewart, \& Mallios, 2006) and communication skills, inexperience with the mental health system (Kates, Lesser, Dawson, Devine, \& Wakefield, 1987), and absence of support for the provider (Mitchell, Del Mar, \& Francis, 2002).

The authors thank Dorrie Fissel, PhD, for designing the audit, surveys, and collection of data. 
Non-psychiatric comorbidities including obesity, metabolic abnormalities, cardiovascular and respiratory diseases, seizures, and tardive dyskineisa are more common among people with mental illness than in the general population, and the treatment of these conditions is complicated by cognitive symptoms and socioeconomic disadvantage. Moreover, stigma limits access and consumers may be reluctant to engage (Craven \& Bland, 2006).

It has been suggested that psychiatrists should assume responsibility for monitoring the physical health of their patients, and that they should liaise with primary care practitioners, address preventive care, monitor metabolic side effects, and treat these risk factors when they appear (Goff, 2007; Sernyak, 2007). However, many locations have a shortage of psychiatric resources, and many psychiatrists feel that they are ill-equipped to handle this additional burden of care (Parks, 2007). While guidelines abound, the development of methods to put them into practice are still in their infancy (Parks, 2007).

In summary, numerous barriers exist in the effective treatment of people with mental illness. Druss and Newcomer (2007) identify the following potential obstacles: (a) geographic-lack of colocated medical and mental health services; (b) financial—separate funding streams for medical and mental health services; (c) organizational-difficulty in sharing information and expertise across these systems; and (d) cultural-providers' focus on particular symptoms or disorders, rather than on the patients. These are common issues that result in treatment that is not only less effective but also more expensive. Other problems arising for people with serious mental illness are frequent use of certain medical services, such as emergency room care, and less contact with primary care services (Druss, 2007).

During the last 10 years, the concept of shared or collaborative care for people with complex and challenging mental illnesses has been explored and developed in Canada and throughout the world. Systematic reviews have demonstrated that a range of collaborative care models can improve patient health and mental health care at a modest cost in Western countries (Druss \& von Esenwein, 2006) and in the developing world (Patel et al., 2007).

\section{WINDSOR-ESSEX COUNTY: THE CASE FOR COLLABORATIVE CARE}

The Canadian Mental Health Association-Windsor Essex County Branch (CMHA-WECB) serves a catchment area that includes both the City of Windsor and the surrounding Essex County; the region has experienced barriers including a lack of medical resources, high demands for service due to an aging population, and high numbers of persons with a serious mental illness. From 1996 to 2001, the population of this area increased by $10.7 \%$ to 387,977 , with $56 \%$ living in Windsor. Of this population, $12.8 \%$ or 48,650 residents were over the age of 65 . The proportion of seniors is expected to increase to $13.5 \%$ by 2010 and to $16.5 \%$ by 2020 . It is estimated that there are 20,100 to 26,800 persons coping with a serious mental illness in Windsor-Essex, including 1,000 to 1,680 residents with chronic disabilities who need ongoing assistance from community support services (Southwest Mental Health Implementation Task Force, 2002).

While many parts of Ontario are underserviced, Essex County is one of the most underserviced communities in the province. Every 3 months, the Ontario Ministry of Health and Long-Term Care publishes a "List of Areas Designated as Underserviced." According to this list, in September 2008 
Windsor-Essex had a designated complement of 233 family physicians; however, 70 positions were vacant. Moreover, this complement is based on 1996 census data, when Windsor-Essex had a population of 321,000 people. Based on the actual population of 405,000 , the vacancies climb to 127 . The Ontario Physician Human Resource Data Centre at McMaster University indicates that the average provincial complement is one family physician for every 1,260 people. Essex County has one family physician per 1,859 residents. A higher percentage of these physicians are working at advanced ages compared with other regions of the province. Their retirements, together with a population increase projected by Statistics Canada to be 426,000 by 2012 , will worsen the situation.

CMHA-WECB staff found that clients without a family physician either ignored their general health or resorted to the emergency department for primary care. The lack of adequate primary care for psychiatric inpatients had been addressed by the local Schedule 1 (i.e., acute care) hospitals through contracts with family practitioners beginning in 1999; however, upon discharge, no primary care followup was provided. Patient care in Windsor-Essex was further compromised by the shortage of psychiatrists and by the separate locations of psychiatrists and family practitioners. It was stressful for clients, and time-consuming for case managers, to attend appointments.

\section{Evolution of Providing Primary Care: Building a Case for Creating a Primary Care Centre}

The concept of a primary care clinic emerged from a "Planning for the Future" exercise conducted by the CMHA-WECB's Strategic Planning and Quality Assurance Task Force. Recognizing the strategic place primary care could occupy in the care of people with mental illness, the task force recommended establishing a Primary Care Working Group charged with the responsibility of exploring options for the future. Initially, the group considered the possibility of developing linkages between mental health providers and family physicians. The shortage of physicians in the community, however, posed a serious limitation. Moreover, physician selection practices often operated against patients with serious mental illness, although the decrease in inpatient beds had intensified the demand for both community mental health services and primary care intervention. At one point in the deliberations, it was suggested that the branch submit a proposal to the Ministry of Health and Long-Term Care to sponsor a primary care clinic. We hypothesized that with access to primary care, clients with mental health problems would have better health outcomes and less need for hospitalization.

CMHA-WECB's proposal to provide primary care met with some resistance in the health and social sectors. Physicians, in particular, were concerned that people would not access primary care services in a community mental health agency and that CMHA-WECB would be unable to attract medical practitioners. They also expressed concerns about client safety and motivation. Through the working group, however, CMHA and many partners were able to work collaboratively to build bridges of understanding, support, and assistance within the health and social services community in Windsor.

\section{The New Clinic}

After investigating a number of models, CMHA-WEBC began to envision a clinic based on both shared mental health care and collaborative care models. Vreeland (2007) suggests that in the new 
mental health care system, both psychiatric and physical health-care providers will need to broaden their treatment paradigm to address the whole person. Because nurses are trained in a holistic approach to care that integrates physical and mental health, they are natural providers of collaborative care (Vreeland, 2007).

CMHA-WEBC hired its first Nurse Practitioner-Extended Class in October 2000. The nurse practitioner joined the existing team of mental health professionals (including nurses, social workers, a psychiatrist, and a psychologist) to provide primary care in collaboration with a consulting physician. She conducted routine assessments and treated non-psychiatric problems, including acute illnesses such as upper respiratory infections and musculoskeletal complaints, and common chronic medical problems such as hypertension and chronic bronchitis. The nurse practitioner also conducted physical examinations, counselled patients about diet, exercise, and substance abuse, and was instrumental in completing applications for disability support. The branch received funding to hire a second nurse practitioner in 2002.

The consulting physician, who was also the hospitalist for the inpatient psychiatry program at Hôtel-Dieu-Grace Hospital, treated patients whose medical needs were outside the nurse practitioner's scope of practice. At the hospital, this physician had experienced the benefits of practicing as a part of a team with less time pressure and a more holistic view of the patient. The physician worked in the clinic five afternoons per week, seeing clients individually as well as consulting with the nurse practitioner and mental health professionals at the branch. In between visits, the physician was available by phone and email. Former inpatients had been recognized as experiencing greater morbidity due to the lack of ongoing primary care, and the shared care clinic began to address this issue.

The clinic incorporated many features that have been shown to be important to improve outcomes for clients. In a recent review of best practices in collaborative mental health care, Craven and Bland (2006) report that preparation, time, supportive structures, and building on pre-existing clinical relationships are key elements in implementing a successful collaborative care approach. Collaborative practice is likely to be most developed when clinicians are co-located and most effective when the location is familiar and non-stigmatizing. Community input, much thought and planning prior to the opening, a pre-existing network of providers, and a location where clients felt at home were all factors in the successful implementation of our primary care clinic.

Through collaboration, the following philosophy emerged:

- Service tailored to the needs of the population. Clients presented with multiple medical and psychiatric problems that were often atypical and required time to adequately investigate. Some clients struggled to explain their symptoms, and they were unable to tolerate stressors such as long waits for service. While conventional office practice is often dominated by time-pressured, problem-focused "piece work," health care providers at the clinic recognized the need to treat the whole person and to maintain flexible schedules.

- Elimination of the "mind-body" split. The clinicians were committed to a holistic approach to assessment and to developing new diagnostic skills. 
- Emphasis on trust and prevention. In addition to dealing with acute problems, clinicians viewed preventative health and establishing relationships of trust with clients as even more critical.

- One-stop shopping for clients. The primary care centre was co-located with mental health services, which meant that clients could access primary care and specialized mental health servicesincluding ombudsman, case managers, employment services, housing, social skills trainers, and psychologists-in the same community setting.

- More efficient use of case managers' time. Provision of care at the clinic benefited case managers who no longer had to wait with their clients for hours in the emergency room.

- Reduction of stigma. Community primary care provision is seen as working to combat stigma by making it easier for individuals to use community resources and programs.

- Consultative role. Clinicians provided consultation to colleagues in the community on mental health issues.

- Collegiality and support. The supportive workplace has promoted the provision of quality health care to a vulnerable population. Team members shared the care of patients with multiple needs, reducing the feelings of isolation and frustration that often occur in private practice.

\section{City Centre Health Care}

In June 2005 the Ministry of Health and Long-Term Care proposed that the CHMA-WECB clinic be funded as a satellite of an existing centre, the Teen Health Centre. The clinic, renamed City Centre Health Care, began to provide a full range of primary and mental health services to 55,306 residents living in the designated catchment area. The population has high numbers of seniors, single parent households, new immigrants, and individuals on some form of social assistance. Services are also available to anyone having a persistent mental illness and without a family physician in the county of Essex. Service provision is holistic and inclusive of family members.

City Centre Health Care serves a general population as well as individuals with serious mental illness. This inclusiveness reflects CMHA-WECB's philosophy of community integration. In addition, many persons have not been diagnosed or are not being treated for their mental health problems (Dewa \& Lin, 2000), and the branch felt that these individuals might be picked up by the community heath centre. The branch also considered that limiting the practice to persons with mental illness might affect staff recruitment and retention.

As of 2008, City Centre Health Care is staffed by one full-time manager, three family physicians (one full-time and two part-time), three nurse practitioners, two therapists, one dietitian, one health promotion specialist, and one nurse. Two and a half positions provide reception and medical secretarial services, and a part-time chiropodist position has been funded but not filled due to space limitations only recently resolved. In addition to these positions, the CMHA-WECB's mental health budget includes separate funding from the Ministry of Health and Long-Term Care for a psychiatrist and a psychologist who also function as members of the collaborative team. 
City Centre Health Care is fully staffed Monday to Friday. The staff nurse triages all calls and ensures that every emergency or medical question is addressed in a timely manner. The centre receives calls on a daily basis from clients wanting to speak with their physician about health concerns and medications. The nurse takes all those calls and provides the support the client needs. Any questions that the nurse cannot answer are passed on to the physician, who returns calls at the end of the shift unless the need is urgent. Referrals are made to the centre through the Canadian Mental Health Association, community programs, and self-referrals. Case conferences are held on an as-needed basis by staff of the City Centre Health Care and the Canadian Mental Health Association to determine and evaluate the course of treatment. Final approval for the construction of a new purpose-built space was received in October 2007.

\section{EVALUATION OF THE INITIAL PRIMARY CARE CLINIC}

In 2002, the CMHA Windsor-Essex County Branch hired a graduate student from the University of Windsor to conduct an evaluation of the primary care services then being provided by one nurse practitioner and one consulting family physician. The purpose of this review was to (a) assess clients' satisfaction with the program, and (b) to determine whether individuals with access to integrated mental health and primary care would be less likely to require care in the emergency room or admission to the hospital. The methodologies included (a) the administration of the Client Perception Survey to users of the services and (b) a retrospective analysis of client records to quantify emergency room visits and hospitalizations. The evaluation followed research policies of the organization and included attention to confidentiality and voluntary consent.

\section{Client Perception Survey Results}

Clients were surveyed to determine their level of satisfaction with the service. In December 2002, 390 surveys were mailed to a sample of clinic clients. Ten surveys were returned undeliverable. The completion rate for the 380 remaining surveys was $45 \%$. Not all questions were completed by all respondents. Data were analyzed using SPSS version 15.0. Percentages were used to summarize categorical variables. Normally distributed continuous variables were described as means and standard deviations.

Highlights from the Client Perception Survey are listed below.

Use of emergency and crisis services. Clients reported a $51.6 \%$ decrease in visits to emergency services. Thirty-eight percent of respondents reported that they had never used emergency services; when their responses are omitted, $83.5 \%$ of clients who previously used emergency services reported a decrease in visits. Clients also reported a $21.6 \%$ decrease in their use of crisis centres, but when the $71 \%$ of clients who had never used crisis services are omitted, the decrease amounts to $75 \%$.

Continuity of service. Although $73 \%$ of clients already had a family doctor, had the CMHAWECB clinic not been available $28 \%$ of these clients stated that they would have attended a walk-in clinic, $41 \%$ would have used other clinics, $13 \%$ would have used hospital emergency rooms, and $17 \%$ either did not know where they would have gone or simply would not have sought medical services. 
Separate surveys were provided to mental health professionals to evaluate continuity of care and other aspects of the service. Most (78.4\%) providers considered the quality of communication with primary care practitioners as either good or excellent. Additionally, 97.8\% agreed or strongly agreed that the nurse practitioner role had contributed to continuity of care.

Client satisfaction. Satisfaction with the service was high. The following quote reflects the thoughts shared by many clients in their survey comments:

Getting complete medical care for this illness has been most beneficial. It is far better coming to a place where the illness is understood than going to doctors where it sometimes is embarrassing. I denied seeking medical attention in the past because of that. Thank you, this is better. (CMHA client)

\section{Retrospective Client Record Review Results}

Results of the retrospective client record review are presented in Tables 1 and 2. Data are based on the records of 805 clients: 395 (49\%) males and 410 (51\%) females. The mean age was 40.7 years $(S D=15.2)$. Most of the clients $(n=707)$ had serious mental illness. Clients with severe chronic depression, followed by bipolar, schizophrenia, and psychosis, formed the predominant profile for psychiatric care (see Table 1). Analysis of the records indicated a reduction in the number of hospitalizations and days spent in hospital. The hospitalization utilization rates were collected preand post-implementation of the clinic. Pre-implementation rates were measured in 2000 and postimplementation in 2001 (see Table 2).

\section{Table 1}

Diagnoses of Community Health Clinic Clients, 2001

\begin{tabular}{lcc}
\hline Diagnosis & $N=805$ & $\%$ \\
\hline Depression & 334 & 41.5 \\
Bipolar disorder & 144 & 17.9 \\
Schizophrenia & 130 & 16.1 \\
Psychosis & 59 & 7.3 \\
Personality disorder & 18 & 2.2 \\
Other & 19 & 2.4 \\
Not specified & 101 & 12.5 \\
\hline
\end{tabular}

Table 2

Changes in Hospitalization Rates Between 2000 and 2001 Based on 805 Client Files

\begin{tabular}{lccc}
\hline Hospital visits & \% Increase & \% Decrease & \% No change \\
\hline Hospitalizations & 8.5 & 75 & 17 \\
Length of stay & 19.2 & 78.8 & 2 \\
\hline
\end{tabular}




\section{DISCUSSION}

While caution is required in interpretation of the data due to the small sample size and limitations of the study (see Limitations section, below), the preliminary findings from the CMHA-WECB experience provide interesting program information and perhaps direction for future research. Despite the obstacles, CMHA-WECB was able to develop a creative solution to the problem of primary care access for its clients.

A review of clinical records demonstrated a reduction in the number of hospitalizations and days in hospital. Clients also reported a reduced dependence on the use of emergency departments, suggesting less use of more expensive sources of care. They reported experiencing greater continuity of care, which may translate into improved health outcomes. The survey indicated that clients did not share physicians' concerns that people would not access primary care services in a community mental health agency. Indeed, the comments of consumers suggest that providing holistic care in a community setting can reduce stigma. Being able to access primary health care is very important for this population, as mental health and physical health are both critical to overall well-being.

Co-locating primary care and mental health services also fostered professional development. Primary care providers at the CHMA-WECB clinic developed specialized skills in mental health care, which supported the mental health professionals and further developed the community capacity of the agency. In the future, it is our hope that interprofessional education and training of all providers will result in a better understanding of the needs of people with mental illness, with the goal of improving patient care and reducing discrimination.

The experience of CMHA Winder-Essex County Branch suggests that established models of health care delivery should be reexamined in light of the needs of persons with mental illness. The systemic limitations that prevent integration and collaboration require remedies. Using a shared mental health care model has the potential to foster an integrated health care system. This system would allow providers to feel more supported, and patients to have access to the appropriate services at the correct time. Above all, a shared care model is likely to lead to a more efficient health care system and better patient outcomes (Kates et al., 1996).

Many of the barriers to collaboration are rooted in the fragmentation of different sectors within the Ministry of Health and Long-Term Care. The establishment of the Local Health Integration Networks might provide opportunities to address these issues and to create more integrated care. Our program offers one example of integrated, collaborative care that has made a tremendous difference in the lives of clients, allowing service providers to offer the best possible care to the person at the appropriate time.

A client satisfaction survey conducted by City Centre Health Care in January 2008 found that presentations at emergency departments have continued to decrease. A total of 191 surveys were completed, and $37 \%$ of clients reported fewer visits to hospital emergency rooms for medical care. Ninetyseven percent of respondents stated that they would refer family members and friends to the centre. In May 2008, despite the inability to accept new clients because of space restrictions, City Centre Health 
Care had 1,227 active clients. With the newly renovated space completed in May 2008, this number is expected to increase.

\title{
LIMITATIONS AND CONCLUSIONS
}

Our clinical records may not have recorded all emergency room visits and hospitalizations. Other factors may have affected the number of visits and hospitalizations, such as changes in the provision of hospital or community services, and these factors were not controlled in our study. The changes in rates of visits and admissions are aggregate data, and therefore these figures may reflect changes in the population served as a whole rather than among clients of the clinic.

Caution is required in interpretation of our survey data because of our small sample size, small convenience sample, heavy emphasis on the subjective data of the clients, and absence of pre- and post-data on the number of emergency visits. Respondents may not accurately represent the group as a whole, limiting the external validity of the results. Further research will be needed to continue to develop the model and to reveal any further trends and changes in our clinical practice.

This paper describes a project that has made primary health care more accessible for individuals with mental illnesses by integrating primary care providers within a mental health setting. We do not wish in any way to overstate our findings, but preliminary findings from the CMHA-WECB experience support the notion that primary health care combined with a mental health intervention has the potential to reduce hospital visits and to improve overall mental and physical health outcomes.

\section{RÉSUMÉ}

\begin{abstract}
Dans plusieurs collectivités, l'un des obstacles qui empêchent les personnes ayant un problème de santé mentale de recevoir le soutien dont elles ont besoin est le manque de soins primaires auxquelles elles ont accès. La filiale de Windsor-Essex County (Ontario) de l'Association canadienne pour la santé mentale a exploré diverses possibilités pour offrir à cette population des soins adéquats, tant physiques que mentaux. On a d'abord créé une clinique de soins primaires intégrés ; ensuite, on a mis sur pied une plus grande clinique de santé où une équipe multidisciplinaire offre également des services de santé mentale. En 2001, l'étude de 805 dossiers médicaux et un sondage auprès des patients ont permis d'évaluer le travail de la clinique. On a ainsi pu observer que, en offrant au même endroit à la fois des soins primaires et des soins de santé mentale, cette clinique communautaire a permis de réduire le nombre de visites et d'admissions à l'urgence, ainsi que d'écourter la durée d'hospitalisation des personnes ayant un problème de santé mentale de moyen à grave. Un nouveau sondage mené auprès des patients en 2008 a confirmé ces résultats.
\end{abstract}

\section{REFERENCES}

Craven, M.A., \& Bland, R. (2006). Better practices in collaborative mental health care: An analysis of the evidence base. Canadian Journal of Psychiatry, 51(Suppl. 1), 7S-72S.

Dewa, C.S., \& Lin, E. (2000). Chronic physician illness, psychiatric disorder and disability in the workplace. Social Science \& Medicine, 51, 41-50.

Druss, B. (2007). Improving medical care for persons with serious mental illness: Challenges and solutions. Journal of Clinical Psychiatry, 68(Suppl. 4), 40-44. 
Druss, B., \& von Esenwein, S.A. (2006). Improving general medical care for persons with mental and addictive disorders: Systematic review. General Hospital Psychiatry, 28, 145-153.

Druss, B.G., \& Newcomer, J.W. (2007). Challenges and solutions to integrating mental and physical health care. Journal of Clinical Psychiatry, 68(4), e09.

Goff, D.C. (2007). Integrating general health care in private community psychiatry practice. Journal of Clinical Psychiatry, 68(Suppl. 4), 49-54.

Kates, N., Craven, M., Bishop, J., Clinton, T., Kraftcheck, D., LeClair, K., et al. (1996). Shared mental health care in Canada. Canadian Journal of Psychiatry, 42(8). Retrieved September 25, 2008, from http:// www.cfpc.ca/English/cfpc/programs/patient\%20care/mental/shared\%20 are/default.asp?s=1

Kates, N., Lesser, A., Dawson, D., Devine, J., \& Wakefield, J. (1987). Psychiatry and family medicine: The McMaster approach. Canadian Journal of Psychiatry, 32, 170-174.

Leigh, H., Stewart, D., \& Mallios, R. (2006). Mental health and psychiatry training in primary care residency programs. Part II. What skills and diagnoses are taught, how adequate, and what affects training directors' satisfaction? General Hospital Psychiatry, 28, 195-204.

Mitchell, G., Del Mar, C., \& Francis, D. (2002). Does primary medical practitioner involvement with a specialist team improve patient outcomes? A systematic review. British Journal of General Practice, 52, 934-939.

Parks, J.J. (2007). Implementing practice guidelines: Lessons from public mental health settings. Journal of Clinical Psychiatry, 68(Suppl. 4), 45-48.

Patel, V., Araya, R., Chatterjee, S., Chisholm, D., Cohen, D., De Silva, M., et al. (2007). Treatment and prevention of mental disorders in low-income and middle-income countries. Lancet, 370(9591), 990-1005.

Sernyak, M.J. (2007). Implementation of monitoring and management guidelines for second-generation antipsychotics. Journal of Clinical Psychiatry, 68(Suppl. 4), 14-18.

Southwest Mental Health Implementation Task Force. (2002). Final report. Prepared for the Minister of Health and Long-Term Care. Retrieved September 25, 2008, from http://www.health.gov.on.ca/english/providers/ pub/mhitf/south_west/south_west.pdf

Unützer, J., Schoenbaum, M., Druss, B.G., \& Katon, W.J. (2006). Transforming mental health care at the interface with general medicine: Report for the president's commission. Psychiatric Services, 57, 37-47.

Vreeland, B. (2007). Bridging the gap between mental and physical health: A multidisciplinary approach. Journal of Clinical Psychiatry, 68(Suppl. 4), 26-33. 